\title{
Neonatal intrahepatic cholestasis due to citrin deficiency
}

INSERM

\section{Source}

INSERM. (1999). Orphanet: an online rare disease and orphan drug data base. Neonatal intrahepatic cholestasis due to citrin deficiency. ORPHA:247598

Neonatal intrahepatic cholestasis due to citrin deficiency is a mild subtype of citrin deficiency (see this term) characterized clinically by low birth weight, failure to thrive, transient intrahepatic cholestasis, multiple aminoacidemia, galactosemia, hypoproteinemia, hepatomeg aly, decreased coagulation factors, hemolytic anemia, variable but mostly mild liver dysfunction, and hypoglycemia. 